\title{
Transpedicular Bi-vertebrae Wedge Osteotomy in Treatment of Post- tubercular Spinal Deformity: A Retrospective Study
}

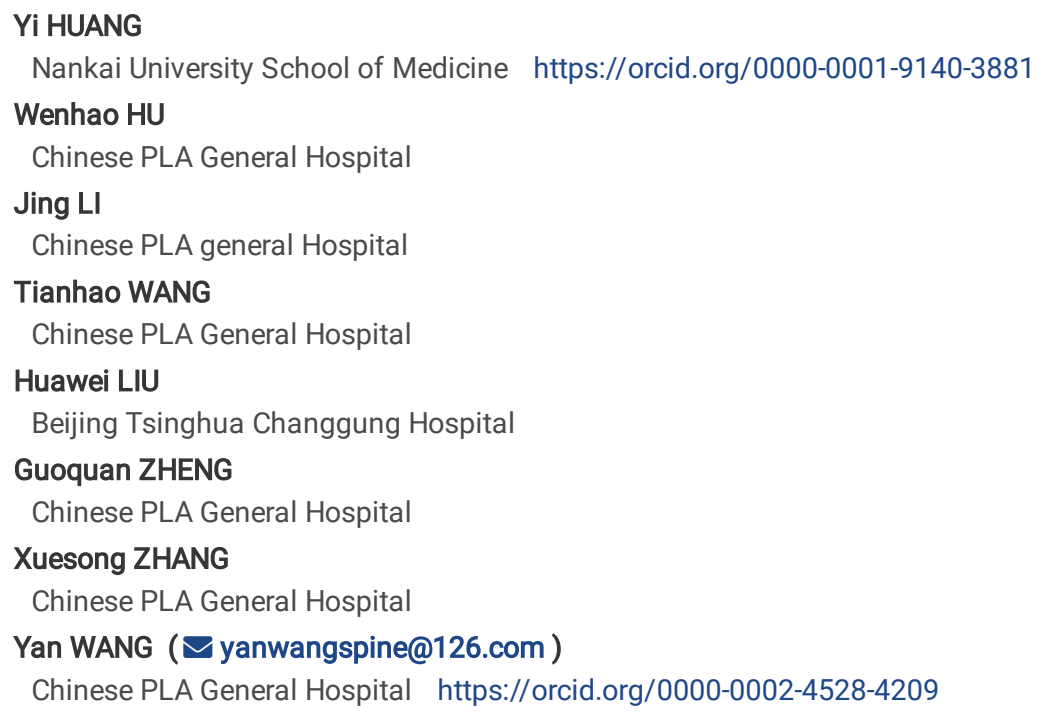

Research article

Keywords: Post-tubercular Spinal Deformity, Osteotomy, Ultrasonic bone scalpel, Retrospective Study

Posted Date: October 21st, 2020

DOI: https://doi.org/10.21203/rs.3.rs-94003/v1

License: (c) (i) This work is licensed under a Creative Commons Attribution 4.0 International License. Read Full License

Version of Record: A version of this preprint was published at BMC Musculoskeletal Disorders on April 12th, 2021. See the published version at https://doi.org/10.1186/s12891-021-04220-w. 


\section{Abstract}

\section{Background:}

In the late stage of spinal tuberculosis, the bony destruction and vertebral collapse often leads to significant kyphosis, presenting clinically as a painful gibbus deformity, with increased instability, vertebral body translations and increased risk of neurologic involvement. Spinal osteotomy is thought to be suitable for most patients with severe rigid kyphosis. The aim of this study was to evaluate the efficacy of transpedicular bi-vertebrae osteotomy technique in the patients with Pott's kyphosis and other post-tubercular spinal deformity.

\section{Methods:}

Between January 2012 and December 2015, 18 patients with post-tubercular spinal deformity underwent the transpedicular bi-vertebrae wedge osteotomy, with a minimum follow up of 27.0 months. Preoperative and postoperative kyphotic angle, sagittal plane parameters (T1-T12 angle for thoracic deformity, T10-L2 angle for thoracolumbar and L1-L5 angle for lumbar deformity) and sagittal vertical axis (SVA) were measured. Oswestry Disability Index (ODI), Visual analog scale (VAS) and modified American Spinal Injury Association grading(ASIA) of preoperative and final follow-up were documented.

\section{Results:}

The average operation time was 455 minutes (range, 200-260 minutes) with a mean intraoperative blood loss of $425 \mathrm{~mL}$ (range, $200-700 \mathrm{~mL}$ ). The kyphotic angles decreased from $80.3^{\circ}$ (range, $28.5^{\circ}-130.8^{\circ}$ ) preoperatively to $26.1^{\circ}$ (range, $7.0^{\circ}-63.3^{\circ}$ ) at the final follow-up (P<0.01). The mean VAS score was reduced from preoperative 5.2(range, 2-9) to 0.9 (range, $0-2, \mathrm{P}<0.01$ ) and the ODI improved from $55.3 \%$ (range, 46\%-76\%) to 6.3\% (range, $2 \%-18 \%, P<0.01)$. At final follow-up, there was radiographic evidence of solid fusion at the osteotomy site and fixed segments in all patients. Neurological function improved from ASIA scale D to $E$ in 7 patients, C to D in 3 patients.

\section{Conclusions:}

Our results suggest that transpedicular bi-vertebrae wedge osteotomy is a safe and effective treatment option for post-tubercular spinal deformity. This technique achieves satisfying correction and fusion rates with adequate decompression of neurological elements.

\section{Background}

Spinal tuberculosis is the most common form of the extra-pulmonary tuberculosis. It accounts for nearly half of the musculoskeletal tuberculosis cases $^{[1]}$. With or without multidrug chemotherapy, residual kyphosis could present. In the late stage, the bony destruction and vertebral collapse often leads to significant kyphosis, presenting clinically as a painful gibbus, creased instability, and the rate of neurological complications is estimated up to $40 \%[2-4]$.

Anterior approach debridement and fusion known as Hong Kong operation reached a good clinical outcome and was a golden standard for active spinal TB. However, when there is bony destruction of spinal column with kyphosis and instability, posterior instrumentation should be considered to achieve a target sagittal alignment. Anterior, posterior, or combined anterior and posterior procedures that show various degrees of success for correcting kyphosis of $\mathrm{TB}^{[5-7]}$.

The late correction of stiff and sharp angular deformities (more than $60^{\circ}$ ) is only feasible with three-column osteotomies or vertebral column resection $(\mathrm{VCR})^{[3]}$. When angular kyphosis is located above thoracic spine, there is a safety concern, significant blood loss and morbidity with major complications. Pedicle subtraction osteotomy (PSO), recommended $30-40^{\circ}$ as a safe range ${ }^{[8]}$, is usually insufficient to correct severe kyphosis. Wang et al. reported satisfying clinical outcomes and over $65^{\circ}$ correction with transpedicular bi-vertebrae wedge osteotomy (TBWO) to manage severe sagittal plane deformity in ankylosing spondylitis ${ }^{[9]}$.

We suppose post-tubercular spinal deformity is a reasonable indication of TBWO ${ }^{[10,11]}$. In present study, we evaluate the clinical and radiographic patient results to estimate the efficacy of this technique applying on post-tubercular deformity.

\section{Methods \\ Study design}

Patients with post-tubercular spinal deformity were admitted to our department from January 2012 to December 2015. Diagnosis was made based on radiographic examination, laboratory tests and histopathology. This study was conducted with approval from the Ethics Committee of Chinese PLA General Hospital and was performed in accordance with the Declaration of Helsinki. Written informed consent was obtained from all participants. The indications for surgery were as follows: (1) low back pain refractory to conservative treatment; (2) being not able to lie down in dorsal position; (3) increasing neurological deficit. Patients with active infection and who cannot tolerate surgery due to poor cardiopulmonary function were excluded. Anteroposterior, lateral spine radiographs, CT 3-D reconstruction, Magnetic Resonance Imaging (MRI) were available for all patients. 
In all, 18 patients of whom (11 males, 7 females; mean age 37.3 years) underwent the TBWO. All patients' morbid segments, osteotomy levels, instrumented levels, operative time and blood loss were noted. (Table 1) The mean kyphotic angle was $80.3^{\circ}$ (ranging from $28.5^{\circ}$ to $130.8^{\circ}$ ) preoperatively. Among the 18 patients, 15 patients underwent an initial debridement without fusion during childhood. Neurologic deficits were assessed according to the American Spinal Injury Association (ASIA) grading system as follows: ASIA E, 4 cases; ASIA D, 9 cases; ASIA C, 4 cases; and ASIA B 1 case. Pain was assessed using the visual analogue score (VAS). Disability status was assessed using the Oswestry Disability Index (ODI). Radiological and clinical records were recorded preoperatively, postoperatively and during the last follow-up period. (Table 2)

Table 1

Demographic and Clinical Data

\begin{tabular}{|c|c|c|c|c|c|c|c|c|}
\hline Patient & Age & Sex & Morbid Segments & Osteotomy Levels & Instrumented Levels & $\begin{array}{l}\text { Operative Time } \\
\text { (min) }\end{array}$ & $\begin{array}{l}\text { Blood Loss } \\
\text { (ml) }\end{array}$ & $\begin{array}{l}\text { Follow-up } \\
\text { (mon) }\end{array}$ \\
\hline 1 & 11 & M & T7-9 & T8,T9 & T5-7,T9-11 & 290 & 700 & 32 \\
\hline 2 & 31 & $M$ & T2-4 & $\mathrm{T} 2, \mathrm{~T} 3$ & C5-6,T1,T5-8 & 430 & 700 & 32 \\
\hline 3 & 42 & M & T7-9 & T8,T9 & T5-7,T9-12 & 340 & 400 & 35 \\
\hline 4 & 31 & $M$ & T2-6 & T3,T4 & $\mathrm{T} 1-6$ & 200 & 400 & 29 \\
\hline 5 & 21 & $\mathrm{~F}$ & T2-3 & T3,T4 & $\mathrm{T} 1-2, \mathrm{~T} 4-6$ & 200 & 200 & 34 \\
\hline 6 & 41 & $M$ & T3-7 & $\mathrm{T} 4, \mathrm{~T} 5$ & T1-3,T7(R),T8-11 & 260 & 500 & 27 \\
\hline 7 & 32 & $M$ & T5-8 & $\mathrm{T} 5, \mathrm{~T} 6$ & T1-4,T8-11 & 400 & 400 & 32 \\
\hline 8 & 56 & $M$ & L2 & L2,L3 & T11-L1,L3-4 & 260 & 300 & 29 \\
\hline 9 & 64 & $\mathrm{~F}$ & $\mathrm{~T} 11-12$ & $\mathrm{~T} 11, \mathrm{~T} 12$ & T8-10,L1-3 & 340 & 200 & 33 \\
\hline 10 & 21 & M & T8-11 & T9,T10 & T5-8,T11-L2 & 430 & 600 & 31 \\
\hline 11 & 44 & $\mathrm{~F}$ & T9-12 & $\mathrm{T} 10, \mathrm{~T} 11$ & T7-10,T12-L3 & 240 & 500 & 30 \\
\hline 12 & 41 & $M$ & T9-11 & T10,T11 & L1(R),L2,T7-9,T11 & 200 & 300 & 32 \\
\hline 13 & 15 & $M$ & T9-L3 & T10,T11 & T9-L3 & 240 & 300 & 31 \\
\hline 14 & 48 & $\mathrm{~F}$ & T11-L3 & $\mathrm{T} 10, \mathrm{~T} 11$ & T8-10,L1-4 & 400 & 600 & 34 \\
\hline 15 & 47 & $\mathrm{~F}$ & T10-12 & $\mathrm{T} 11, \mathrm{~T} 12$ & T7-10,T12-L3 & 230 & 250 & 32 \\
\hline 16 & 38 & $\mathrm{~F}$ & L3-4 & L3,L4 & L1-3,L5-S1,S2(L) & 230 & 400 & 28 \\
\hline 17 & 65 & $M$ & T12-L3 & T12,L1 & T4-11,L4-S1 & 420 & 300 & 36 \\
\hline 18 & 24 & $\mathrm{~F}$ & L1-4 & L3,L4 & T8-L1,L4-5 & 380 & 600 & 29 \\
\hline
\end{tabular}


Table 2

The preoperative, postoperative and last follow-up data

\begin{tabular}{|c|c|c|c|c|c|c|c|c|c|c|c|c|c|c|c|}
\hline \multirow[t]{3}{*}{ Patient } & \multicolumn{2}{|c|}{$\begin{array}{l}\text { Kyphotic } \\
\text { angle } \\
\left({ }^{\circ}\right)\end{array}$} & \multirow[t]{3}{*}{$\begin{array}{l}\text { Correction } \\
\left({ }^{\circ}\right)\end{array}$} & \multirow{3}{*}{$\begin{array}{l}\text { Type } \\
T^{*}, T L^{*}, L^{*}\end{array}$} & \multicolumn{2}{|c|}{$\begin{array}{l}\text { Sagittal } \\
\text { plane } \\
\text { parameters } \\
\text { (pre, post) }\end{array}$} & \multirow[t]{3}{*}{$\begin{array}{l}\text { Correction } \\
\left(^{\circ}\right)\end{array}$} & \multicolumn{2}{|l|}{ SVA } & \multicolumn{2}{|c|}{ ASIA } & \multicolumn{2}{|l|}{$\begin{array}{l}\text { ODI } \\
\text { (\%) }\end{array}$} & \multicolumn{2}{|l|}{ VAS } \\
\hline & \multirow[t]{2}{*}{ Pre- } & \multirow[t]{2}{*}{ Post- } & & & \multirow{2}{*}{\multicolumn{2}{|c|}{$\begin{array}{l}\text { T1-T12/T10- } \\
\text { L2 } \\
\text { /L1-L5 angle }\end{array}$}} & & \multirow[t]{2}{*}{ Pre- } & \multirow[t]{2}{*}{ Post- } & \multirow[t]{2}{*}{ Pre- } & \multirow[t]{2}{*}{$\begin{array}{l}\text { F- } \\
\text { follow }\end{array}$} & \multirow[t]{2}{*}{ Pre- } & \multirow[t]{2}{*}{$\begin{array}{l}\text { F- } \\
\text { follow }\end{array}$} & \multirow[t]{2}{*}{ Pre- } & \multirow[t]{2}{*}{$\begin{array}{l}\text { F- } \\
\text { follow }\end{array}$} \\
\hline & & & & & & & & & & & & & & & \\
\hline 1 & 78.5 & 34.0 & 44.5 & $\mathrm{~T}$ & 25.4 & 30.8 & -5.4 & -4.2 & 3.2 & $C$ & D & 76 & 12 & 7 & 1 \\
\hline 2 & 77.0 & 11.3 & 65.7 & $\mathrm{~T}$ & 95.8 & 42.7 & 53.1 & 0.1 & 1.6 & $\mathrm{C}$ & $D$ & 68 & 8 & 2 & 0 \\
\hline 3 & 110.2 & 63.3 & 46.9 & $\mathrm{~T}$ & 62.3 & 35.8 & 26.5 & 1.75 & 4.7 & $D$ & $E$ & 48 & 2 & 3 & 1 \\
\hline 4 & 50.5 & 30.2 & 20.3 & $\mathrm{~T}$ & 57.9 & 47.3 & 10.6 & -7.9 & 0.5 & $C$ & $E$ & 62 & 18 & 2 & 0 \\
\hline 5 & 28.5 & 15.3 & 13.2 & $\mathrm{~T}$ & 30.6 & 19.3 & 11.3 & 5.5 & -1.7 & B & $C$ & 62 & 6 & 2 & 0 \\
\hline 6 & 127.6 & 40.1 & 87.5 & $\mathrm{~T}$ & 61.5 & 0.3 & 61.2 & 4.5 & 2.5 & $C$ & $D$ & 52 & 6 & 4 & 1 \\
\hline 7 & 98.0 & 49.2 & 48.8 & $\mathrm{~T}$ & 81.3 & 42.9 & 38.4 & -1.2 & 0.1 & $\mathrm{D}$ & $E$ & 46 & 2 & 9 & 2 \\
\hline 8 & 67.0 & 21.0 & 46.0 & TL & 67.0 & 25.0 & 42.0 & 0.5 & 3.0 & $D$ & $E$ & 48 & 6 & 8 & 1 \\
\hline 9 & 31.7 & 10.0 & 21.7 & $\mathrm{TL}$ & 29.0 & 24.0 & 5.0 & -4 & 3.1 & $E$ & $E$ & 46 & 4 & 9 & 2 \\
\hline 10 & 84.0 & 22.3 & 61.7 & $\mathrm{TL}$ & 61.6 & 2.0 & 59.6 & -0.8 & -0.2 & D & $E$ & 60 & 6 & 6 & 2 \\
\hline 11 & 85.0 & 14.6 & 70.4 & TL & 72.5 & 0.4 & 72.1 & 5.2 & 3.1 & $D$ & $E$ & 52 & 10 & 7 & 2 \\
\hline 12 & 80.6 & 23.1 & 57.5 & $\mathrm{TL}$ & 66.0 & 8.0 & 58.0 & 1.0 & 2.9 & $D$ & $D$ & 52 & 6 & 7 & 1 \\
\hline 13 & 54.4 & 30.9 & 23.5 & $\mathrm{TL}$ & 68.6 & 27.3 & 41.3 & -6.4 & -1.8 & $E$ & $\mathrm{E}$ & 50 & 4 & 2 & 0 \\
\hline 14 & 130.8 & 48.0 & 82.8 & $\mathrm{TL}$ & 59.5 & 40.0 & 19.5 & 8.5 & 3.3 & D & $E$ & 52 & 6 & 3 & 0 \\
\hline 15 & 70.5 & 13.4 & 57.1 & $\mathrm{TL}$ & 67.8 & 14.5 & 53.3 & -5.9 & 3.9 & $E$ & $E$ & 48 & 2 & 7 & 1 \\
\hline 16 & 68.9 & 10.6 & 58.3 & $\mathrm{~L}$ & -36.0 & 10.1 & -46.1 & 11.5 & -0.8 & $D$ & $\mathrm{D}$ & 76 & 10 & 6 & 1 \\
\hline 17 & 106.0 & 26.0 & 80.0 & $L$ & -60.2 & 2.0 & -62.2 & 12.5 & 4.5 & D & $E$ & 52 & 4 & 3 & 1 \\
\hline 18 & 95.6 & 7.0 & 88.6 & $\mathrm{~L}$ & -70.5 & 4.0 & -74.5 & 32.7 & 1.0 & $E$ & $E$ & 46 & 2 & 7 & 1 \\
\hline
\end{tabular}

\section{Operative technique}

All surgeries were performed under monitoring of somatosensory-evoked potentials, transcranial motor-evoked potentials, and free-running electromyography. Under general anesthesia, the patient was placed prone on the operating table, and a standard posterior middle incision was made at the predetermined level. The spine was exposed by dissection lateral to the costotransverse joint at the thoracic level and transverse process of the lumbar. The segmental vessels were coagulated using electric cauterization and hemostatic gauze. Pedicle screws (Weigao Orthopedic,Shandong, China)were then placed three levels above and below the damaged vertebral body by freehand technique. C-arm fluoroscopy was used to confirm the appropriate insertions.

With ultrasonic bone scalpel (UBS, Weigao Orthopedic,Shandong, China), posterior elements including the spinous process, bilateral lamina, transverse process, and the adjacent facet joints were removed. (Fig. 1a) The pedicle probe and curette were used to create and enlarge the pedicle holes of the fused malformed vertebras with both sides of the pedicles. (Fig. 1b) Gelatin sponges were placed into the holes for hemostasis. Then posterior part of pedicles were removed and the spinal canal was opened laterally. For thoracic segments, nerve root ligation shall be performed if there is a high tension in dura sac.

For malformed vertebrae which containing more than 2 pairs of pedicles, through a relatively larger pedicle holes, wedge osteotomies were performed as designed preoperatively. Removing lower and upper endplate and relic of disc between them when necessary. The ultrasonic bone scalpel was used to make thinning of the anterior cortex and lateral walls of vertebral body. After removing the posterior cortical bone of the osteotomised vertebra, the kyphotic spine is corrected using gentle manual force stabilized by a temporary rod. The operating table and the position of the patient were adjusted for the correction. (Fig. 2) 
After confirmation of absent soft or bony compression, a drainage tube was placed in the surgical field, and the wound was closed in layer sequence.

\section{Statistical analysis}

All statistical analysis was performed with SPSS v19.0 software (SPSS Inc., Chicago, Illinois). Students' t-test was used for all analyses, and a p-value < 0.05 was considered statistically significant.

\section{Results}

TBWO was performed in all patients. All patients completed follow-up of 31.4 months on average, from 27 to 36 months. The average operative time was 305 minutes (range, 200-430 minutes) with a mean intraoperative blood loss of $425 \mathrm{~mL}$ (range, 200-700 mL). The kyphotic angles decreased from $80.3^{\circ}$ (range, $28.5^{\circ}-130.8^{\circ}$ ) preoperatively to $26.1^{\circ}$ (range, $7.0^{\circ}-63.3^{\circ}$ ) at the final follow-up $(\mathrm{P}<0.01)$. T1-T12 angle of thoracic type kyphosis decreased from $59.3^{\circ}$ (range, $25.4^{\circ}-95.8^{\circ}$ ) to 31.3 (range, $0.3^{\circ}-47.3^{\circ}$ ). T10-L2 angle of thoracolumbar type kyphosis decreased from $61.5^{\circ}\left(\right.$ range, $29.0^{\circ}-$ $72.5^{\circ}$ ) to $17.7^{\circ}$ (range, $0.4^{\circ}-40.0^{\circ}$ ). L1-L5 angle of lumbar type kyphosis decreased from $-55.6^{\circ}$ (range, $-70.5^{\circ}--36.0^{\circ}$ ) to $5.4^{\circ}\left(\right.$ range, $2.0^{\circ}-10.1^{\circ}$ ). The preoperative and final follow-up data of the 18 patients were shown in Table 2.

The mean VAS score was reduced from preoperative 5.2 (range, 2-9) to 0.9 (range, $0-2, \mathrm{P}<0.01$ ) and the ODI improved from $55.3 \%$ (range, $46-76 \%$ ) to $6.3 \%$ (range, $2-18 \%, P<0.01$ ). At final follow-up, there was radiographic evidence of solid fusion at the osteotomy site and fixed segments in all patients. (Fig. 3 and Fig. 4) Neurological function improved from ASIA scale D to E in 7 patients, C to D in 3 patients.

Dural tears with transient cerebrospinal fluid leakage were encountered in 1 case who underwent an initial debridement, the tear was covered intraoperatively by muscle and fat grafts, lumbar drainage was placed and removed after seven days. No deep wound infection was identified. One patient suffered transient partial neurological deficit (quadriceps paralysis) post-operatively and resolved completely after 3 months.

\section{Discussion}

TB spondylitis is still a tricky problem in both developing and developed countries ${ }^{[12]}$, which can lead to a significant bone destruction and collapse of the vertebral bodies, resulting in hyper-kyphosis and tethering of the spinal cord ${ }^{[3,11]}$.For patients with neurological deficits, spinal instability or severe kyphotic deformity, surgery should be considered ${ }^{[3]}$. The sharp angular hyper-kyphosis often requires complex three-column osteotomies. Currently, the one-stage posterior approach is most often used for minimizing the risk of injury to anterior vascular and visceral structures ${ }^{[13]}$. Pedicle subtraction osteotomy (PSO), the most popular osteotomy technique, has been applied for progressive tubercular thoracic and thoracolumbar kyphosis. Kalra et $\mathrm{al}^{[10]}$ used pedicle subtraction osteotomy to treat patients with healed tuberculosis of the spine and a resultant kyphosis. The osteotomy is described as closing wedge osteotomy and correction of the deformity is achieved by the shortening of posterior column. However, the technique should be limited to $30^{\circ}-40^{\circ}$ as a safe range of single segment osteotomy; otherwise, the spinal cord is excessively shortened and distorted ${ }^{[14]}$. Some modifications of PSO are reported that could obtain a greater correction angle without postoperative complications ${ }^{[15]}$ and Wu SS et al. ${ }^{[16]}$ claimed that they obtain a maximum correction angle of $60^{\circ}$ at a single level. However, it is not suitable to correct a severe kyphotic deformity with a kyphotic angle beyond $90^{\circ}$.

Although Posterior VCR provides adequate amount of surgical correction when compared to all other spinal osteotomy types ${ }^{[17]}$, it is restricted owing to its inevitable neurological risk related to the instability induced during correction of the malformation ${ }^{[18,19]}$. The complication rate has been estimated as high as $59 \%$ for posterior VCR ${ }^{[20]}$. Zheng et al. ${ }^{[21]}$ described Posterior-only bilevel modified vertebral column resection for extremely severe Pott's kyphotic deformity, and the spinal sagittal kyphotic angle was corrected from a preoperative kyphosis $100.3^{\circ}$ to a postoperative angle of $15.9^{\circ}$ in their study. This procedure, however, was recommend to be performed at or below lower thoracic spine for security concerns. Transpedicular bi-vertebrae wedge osteotomy (TBWO) was first applied for fixed sagittal deformity of ankylosing spondylitis by Wang et al ${ }^{[9]}$, and they achieved an average correction of $65.2^{\circ}$. Same technique was applied in Zhao's research and achieved a $76.8 \%$ correction of the sagittal imbalance ${ }^{[22]}$. It should be noticed that TBWO could effectively reconstruct regional alignment than many other posterior osteotomy techniques. And this technique allows spacious room for neural elements and direct vision during osteotomy procedure, thus it can be safely applied in cervical or cervicothoracic area.

For those with upper post-tubercular spinal deformity, we prefer the TBWO in several aspects. First, most post-tubercular fused vertebras were angular deformity, which were treated as one targeted vertebra so that one-level osteotomy could obtain satisfactory outcomes, so it could reasonably reduce operation time and blood loss. Secondly, collapse of anterior cortex of the osteotomy vertebra facilitates the correction of a rigid kyphosis ${ }^{[23]}$, and larger bony contact surface could provide better fusion rates and additional spinal stability. Thirdly, TBWO could allow greater correction angles for its sufficient decompression of posterior elements, especially for upper thoracic and cervical segments. When angular kyphosis deflexed, dura sac expanded and folded backwards, without obvious axial shortening. In our study, the average correction angle was $54.1^{\circ}$, and the maximum correction angle was $88.6^{\circ}$. One quadriceps paralysis was observed and recovered 3 months later postoperatively. And there was one dura tears case with no postoperative infection. All of the 18 patients with post-tubercular spinal deformity who underwent TBWO achieved steady fusions, satisfactory rehabilitation and no permanent neurological complications occurred.

In a decade ago, high-speed drill was commonly used in bone removing. However, when close to dura and nerve roots, a downward pressure of drill could be dangerous and disastrous neurological complications could happen. Especially in angular kyphosis, dura was stretched and high-tension, which closely clung to bony structure, and epidural space is extremely narrow. UBS applied in spine surgery has a huge advantage in time saving, 
minimizing soft tissues injury and could precisely finish bone cutting ${ }^{[24-26]}$. Utilization of UBS in osteotomy procedure can be safe and compatible in transpedicular bone removing, and leaves a smooth surface, which give less chance of dura tear and nerve injury. However, further research is needed to investigate the impact of UBS heat effect during osteotomy on bony fusion.

\section{Conclusions}

Our results suggest that TBWO technique is a safe and effective treatment option for post-tubercular spinal deformity. This technique achieves satisfying correction and fusion rates with adequate decompression of neurological elements.

\section{Abbreviations}

TB: tuberculosis; TBWO: transpedicular bi-vertebrae wedge osteotomy; VCR: vertebral column resection; PSO: Pedicle subtraction osteotomy; UBS: ultrasonic bone scalpel; ASIA: American Spinal Injury Association grading system; VAS: visual analogue score; ODI: Oswestry Disability Index; CT: computerized tomography; MRI: Magnetic Resonance Imaging.

\section{Declarations}

\section{Ethics approval and consent to participate}

This study was conducted with approval from the Ethics Committee of Chinese PLA General Hospital and was performed in accordance with the Declaration of Helsinki. Written informed consent was obtained from all participants.

\section{Consent for publication}

We have obtained consent to publish from the participants.

\section{Availability of data and materials}

The patients' data were collected in the Chinese PLA General Hospital. The datasets used and/or analyzed during the current study are available from the corresponding author on reasonable request.

\section{Competing interests}

The authors declare that they have no competing interests

\section{Funding}

No funding was received in support of this work.

\section{Authors' contributions}

All authors have read and approved the final manuscript. YH was involved in the study design, data collection, drafting and revising of the manuscript. WH was involved in the study design, analysis and interpretation of the data, drafting and revising of the manuscript. JL, TW and $\mathrm{HL}$ were involved in the data collection. JL and GZ were involved in the analysis and interpretation of data. XZ was involved in the study design, data collection, analysis and interpretation of the data. YW was involved in the study design, drafting and revising of the manuscript and has given final approval.

\section{Acknowledgements}

Not applicable.

\section{References}

1. Yao DC, Sartoris DJ. Musculoskeletal tuberculosis. Radiol Clin North Am. 1995. 33(4): 679-89.

2. Jain AK, Aggarwal PK, Arora A, Singh S. Behaviour of the kyphotic angle in spinal tuberculosis. Int Orthop. 2004. 28(2): 110-4.

3. Boachie-Adjei O, Papadopoulos EC, Pellisé F, et al. Late treatment of tuberculosis-associated kyphosis: literature review and experience from a SRSGOP site. Eur Spine J. 2013. 22 Suppl 4: 641-6.

4. Jain AK, Kumar J. Tuberculosis of spine: neurological deficit. Eur Spine J. 2013. 22 Suppl 4: 624-33.

5. Song JF, Jing ZZ, Chen B, Ai ZS, Hu W. One-stage anterolateral surgical treatment for lumbosacral segment tuberculosis. Int Orthop. 2012. 36(2): 339-44.

6. Pang X, Wu P, Shen X, Li D, Luo C, Wang X. One-stage posterior transforaminal lumbar debridement, $360^{\circ}$ interbody fusion, and posterior instrumentation in treating lumbosacral spinal tuberculosis. Arch Orthop Trauma Surg. 2013. 133(8): 1033-9. 
7. He Q, Xu J. Comparison between the antero-posterior and anterior approaches for treating L5-S1 vertebral tuberculosis. Int Orthop. 2012. 36(2): 345-51.

8. Kawahara N, Tomita K, Kobayashi T, Abdel-Wanis ME, Murakami H, Akamaru T. Influence of acute shortening on the spinal cord: an experimental study. Spine (Phila Pa 1976). 2005. 30(6): 613-20.

9. Wang Y, Zhang Y, Mao K, et al. Transpedicular bivertebrae wedge osteotomy and discectomy in lumbar spine for severe ankylosing spondylitis. J Spinal Disord Tech. 2010. 23(3): 186-91.

10. Kalra KP, Dhar SB, Shetty G, Dhariwal Q. Pedicle subtraction osteotomy for rigid post-tuberculous kyphosis. J Bone Joint Surg Br. 2006. 88(7): 9257.

11. Charles YP, Schuller S, Sfeir G, Steib JP. Vertebral column resection for thoracic hyperkyphosis in Pott's disease. Eur Spine J. 2014. 23(3): 708-10.

12. Zumla A, Raviglione M, Hafner R, von Reyn CF. Tuberculosis. N Engl J Med. 2013. 368(8): 745-55.

13. Wang LJ, Zhang HQ, Tang MX, Gao QL, Zhou ZH, Yin XH. Comparison of Three Surgical Approaches for Thoracic Spinal Tuberculosis in Adult: Minimum 5-Year Follow Up. Spine (Phila Pa 1976). 2017. 42(11): 808-817.

14. Gertzbein SD. Scoliosis Research Society. Multicenter spine fracture study. Spine (Phila Pa 1976). 1992. 17(5): 528-40.

15. Hong-Qi Z, Yong C, Jia H, Chaofeng G, Xiongke H. Modified pedicle subtraction osteotomies (mPSO) for thoracolumbar post-tubercular kyphosis in pediatric patients: retrospective clinical cases and review of the literature. Childs Nerv Syst. 2015. 31(8): 1347-54.

16. Wu SS, Hwa SY, Lin LC, Pai WM, Chen PQ, Au MK. Management of rigid post-traumatic kyphosis. Spine (Phila Pa 1976). 1996. 21(19): 2260-6; discussion 2267.

17. Enercan M, Ozturk C, Kahraman S, Sarıer M, Hamzaoglu A, Alanay A. Osteotomies/spinal column resections in adult deformity. Eur Spine J. 2013. 22 Suppl 2: S254-64.

18. Liu S, Zhang N, Song Y, et al. Radiologic comparison of posterior release, internal distraction, final PSO and spinal fusion with one-stage posterior vertebral column resection for multi-level severe congenital scoliosis. BMC Musculoskelet Disord. 2017. 18(1): 270.

19. Leatherman KD, Dickson RA. Two-stage corrective surgery for congenital deformities of the spine. J Bone Joint Surg Br. 1979. 61-B(3): 324-8.

20. Lenke LG, Newton PO, Sucato DJ, et al. Complications after 147 consecutive vertebral column resections for severe pediatric spinal deformity: a multicenter analysis. Spine (Phila Pa 1976). 2013. 38(2): 119-32.

21. Wang Y, Zhang Y, Zhang X, et al. Posterior-only multilevel modified vertebral column resection for extremely severe Pott's kyphotic deformity. Eur Spine J. 2009. 18(10): 1436-41.

22. Zhao Y, Xu H, Zhang Y, Wang Z, Zhang X, Wang Y. Comparison of two surgeries in treatment of severe kyphotic deformity caused by ankylosing spondylitis: Transpedicular bivertebrae wedge osteotomy versus one-stage interrupted two-level transpedicular wedge osteotomy. Clin Neurol Neurosurg. 2015. 139: 252-7.

23. Zhang $X$, Zhang Z, Wang J, et al. Vertebral column decancellation: a new spinal osteotomy technique for correcting rigid thoracolumbar kyphosis in patients with ankylosing spondylitis. Bone Joint J. 2016. 98-B(5): 672-8.

24. Nakagawa H, Kim SD, Mizuno J, Ohara Y, Ito K. Technical advantages of an ultrasonic bone curette in spinal surgery. J Neurosurg Spine. 2005. 2(4): 431-5.

25. Hazer DB, Yaşar B, Rosberg HE, Akbaş A. Technical Aspects on the Use of Ultrasonic Bone Shaver in Spine Surgery: Experience in 307 Patients. Biomed Res Int. 2016. 2016: 8428530.

26. Sanborn MR, Balzer J, Gerszten PC, Karausky P, Cheng BC, Welch WC. Safety and efficacy of a novel ultrasonic osteotome device in an ovine model. J Clin Neurosci. 2011. 18(11): 1528-33.

\section{Figures}




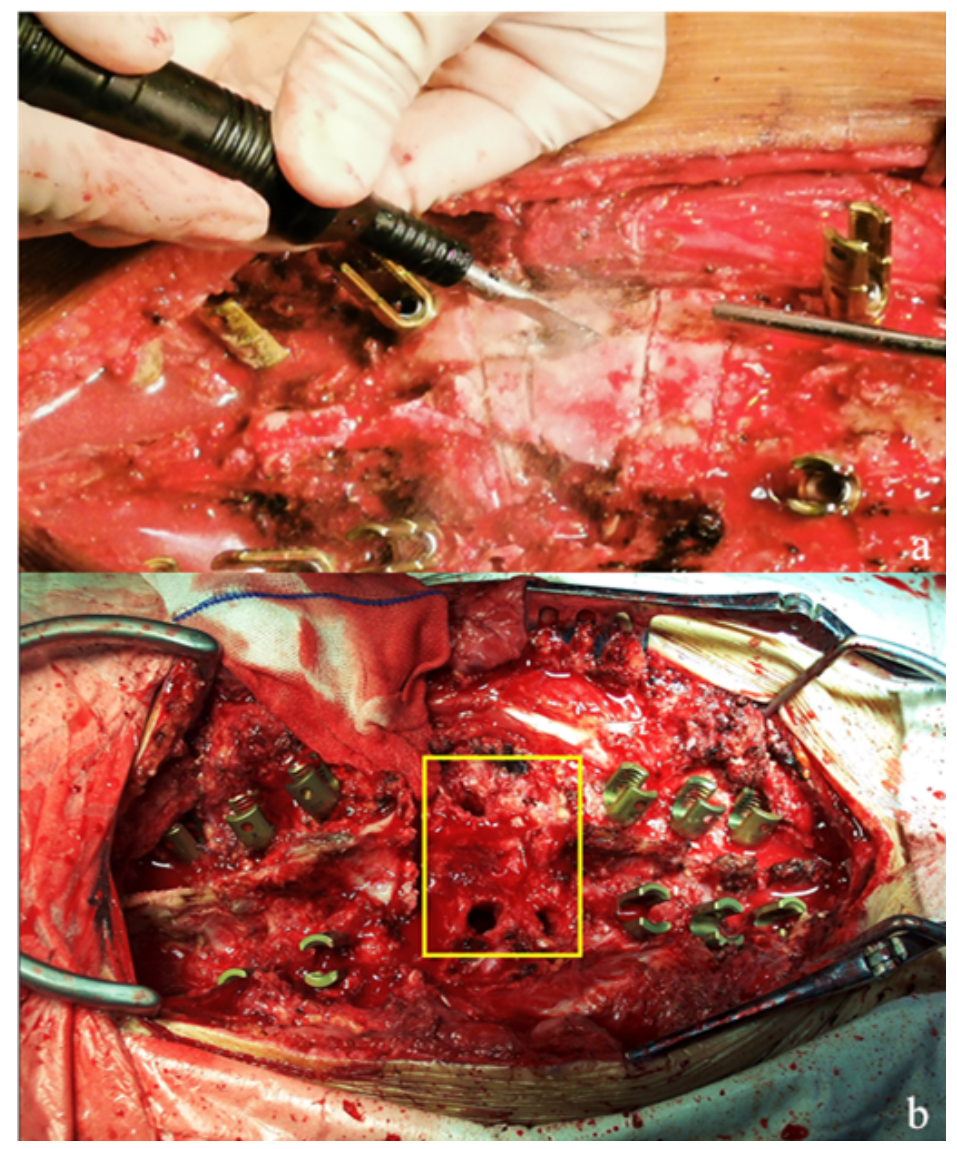

\section{Figure 1}

a. Posterior elements were removed with ultrasonic bone scalpel. b. The pedicle holes (yellow frame) of the malformed vertebras were created and enlarged utilizing the probe and curette. 


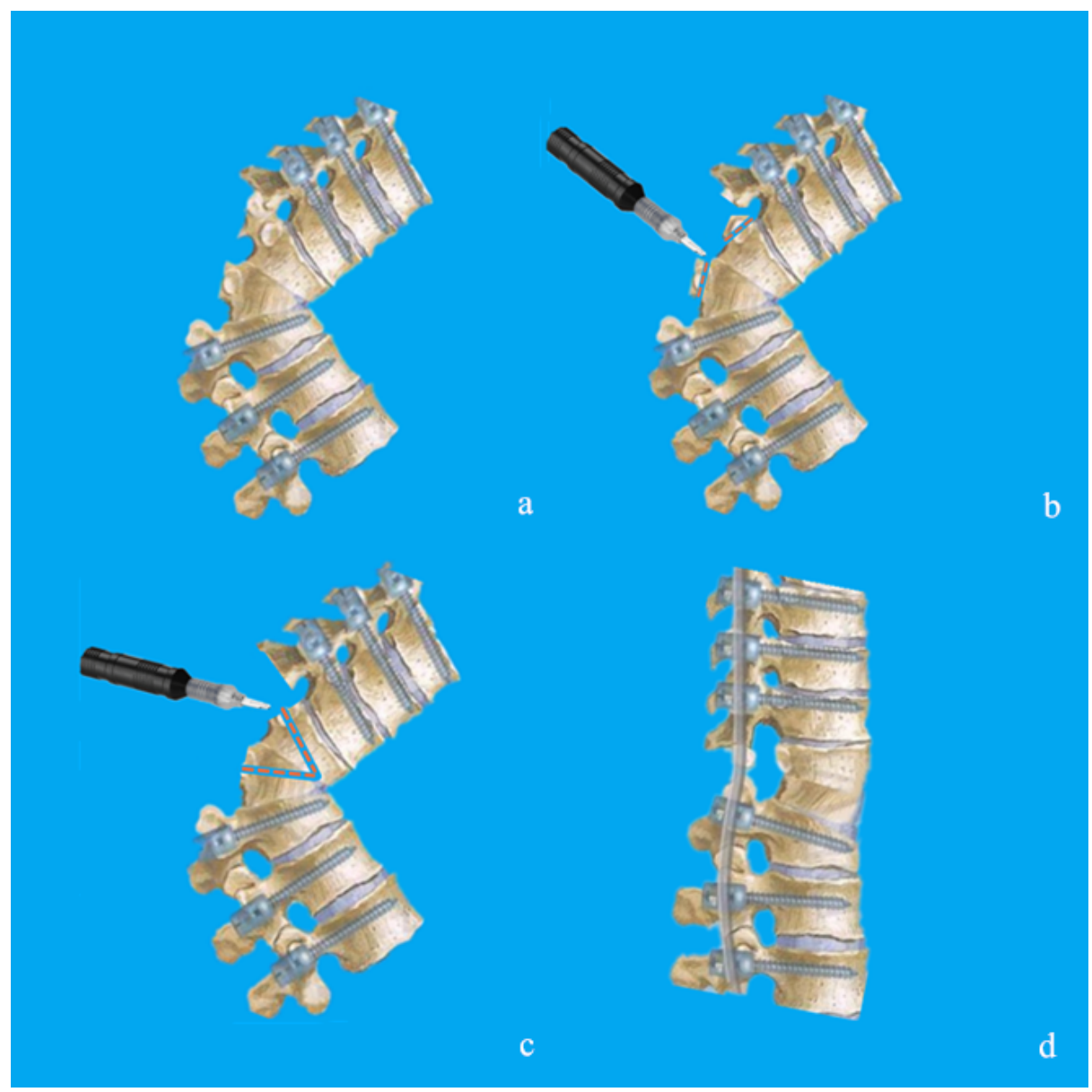

\section{Figure 2}

a. Pedicle screws were placed and posterior elements were removed with ultrasonic bone scalpel. b. Posterior part of pedicles were removed and the spinal canal was opened laterally. c. Wedge osteotomies were performed as designed preoperatively including lower and upper endplate and relic of disc between them. d. After removing the posterior cortical bone of the osteotomised vertebra, the kyphotic spine is corrected using gentle manual force stabilized by a temporary rod. 


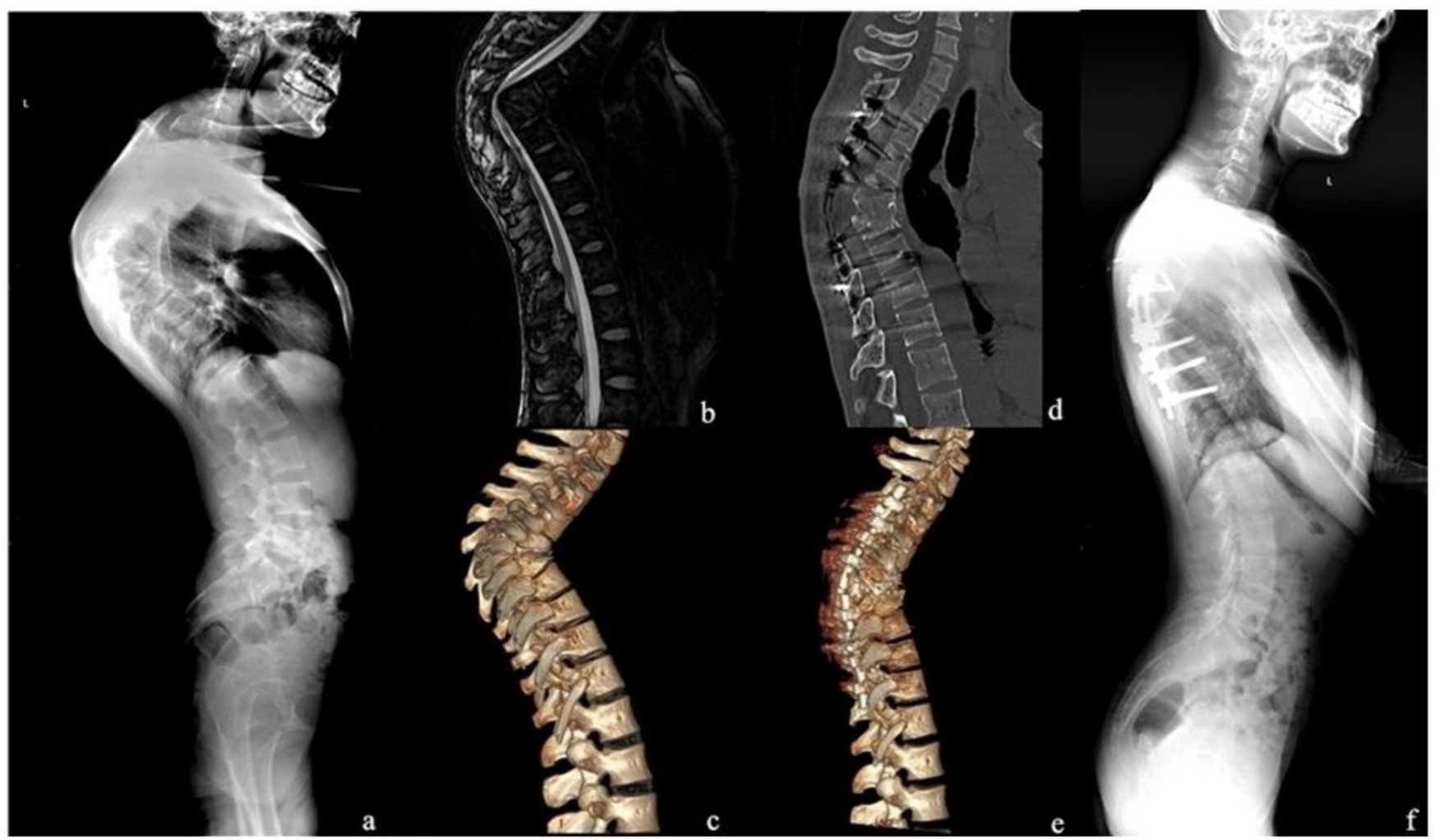

Figure 3

(a, b, c). A 32 years old male patient presented with lower limb numbness and mobility restricted. T5-8 spinal column collapsed and deformation, kyphotic angle was $98.0^{\circ}$ and SVA was measured $-1.2 \mathrm{~cm}$ preoperatively. (d, e, f). The transpedicular bi-vertebrae wedge osteotomy was performed in T5 and T6. A correction of $48.8^{\circ}$ was achieved in upper thoracic region safely. The patient improved to ASIA E after 6 months, and solid fusion was observed in final follow-up.

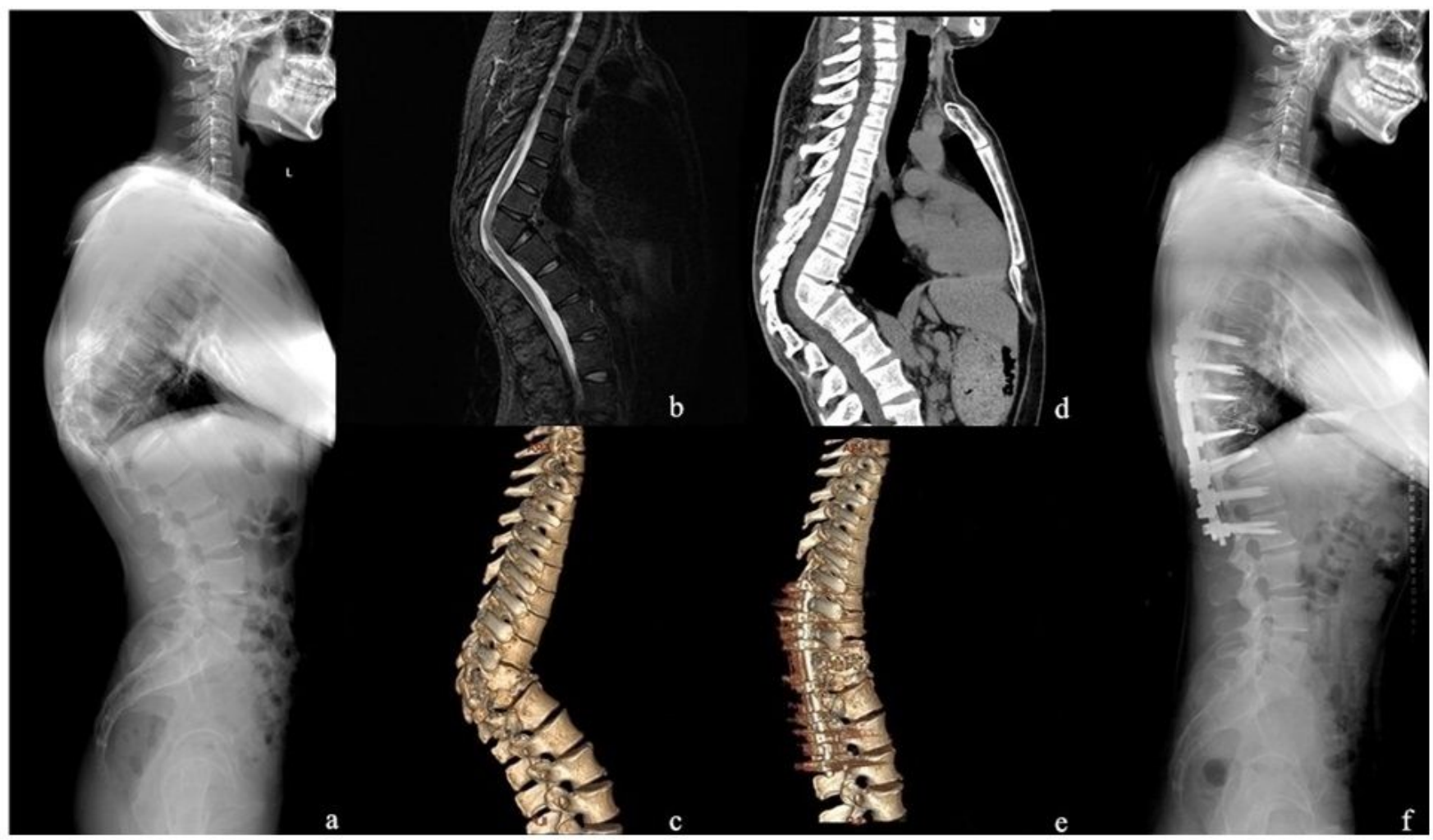

Figure 4 
(a, b, c, d). A 41 years old male patient, presenting with severe back and radicular pain, without cord compression symptom. Anterior column collapse in lower thoracic region. The kyphotic angle of T9-11 was $80.6^{\circ}$ and SVA was measured $1.0 \mathrm{~cm}$ preoperatively. (e,f). The transpedicular bi-vertebrae wedge osteotomy was performed in T9 and T10. A postoperative kyphotic angle of $23.1^{\circ}$ and better sagittal alignment were achieved. Notably, an extra cage was placed in lower intervertebral space to keep height of it. 